\title{
Association between Helicobacter pylori infection and delayed growth in children: A meta-analysis
}

\author{
SHUCHUN WEI ${ }^{*}$, YINI DANG ${ }^{1 *}$, LEI PENG $^{1 *}$, XUAN LI $^{1}$, LIMING TANG $^{2}$ and GUOXIN ZHANG ${ }^{1}$ \\ ${ }^{1}$ Department of Gastroenterology, The First Affiliated Hospital of Nanjing Medical University, Nanjing, Jiangsu 210029; \\ ${ }^{2}$ Department of General Surgery, Changzhou No. 2 People's Hospital, Changzhou, Jiangsu 213000, P.R. China
}

Received September 17, 2019; Accepted March 17, 2020

DOI: $10.3892 /$ etm.2020.8654

\begin{abstract}
Helicobacter pylori (H. pylori) infection is associated with extra-gastrointestinal diseases in children. The present study aimed to investigate the potential association between $H$. pylori infection and growth in children. The PubMed, Exerpta Medica dataBASE, Cochrane Library and Chinese Biomedical Literature Database databases were comprehensively searched for relevant publications dated between January 1st 1994 and January 1st 2019. Delayed childhood growth was defined according to the age-appropriate criteria in the World Health Organization Child Growth Charts (2006 edition). The odds ratios (ORs) and $95 \%$ CIs were pooled using the fixed-effects model and subgroup and sensitivity analyses were performed using Review Manager (version 5.3; Cochrane) and STATA (version 12.0; StataCorp LP) software. A total of 15 observational studies comprising 4,199 subjects were included in the present study. A higher frequency of delayed growth was observed in $H$. pylori-positive children compared with that in $H$. pylori-negative children (OR, 1.51; 95\% CI, 1.28-1.78), particularly for linear growth (OR, 1.63; 95\% CI, 1.32-2.00). The aforementioned association was only observed when $H$. pylori infection was detected using ${ }^{13} \mathrm{C}$-urea breath tests (OR, 1.72; 95\% CI, 1.22-2.40) or serum IgG antibodies targeted against $H$. pylori (OR, 1.81; 95\% CI, 1.35-2.44).
\end{abstract}

Correspondence to: Dr Guoxin Zhang, Department of Gastroenterology, The First Affiliated Hospital of Nanjing Medical University, 300 Guangzhou Road, Nanjing, Jiangsu 210029, P.R. China E-mail: guoxinz@njmu.edu.cn

Dr Liming Tang, Department of General Surgery, Changzhou No. 2 People's Hospital, 29 Xinglong Lane, Changzhou, Jiangsu 213000, P.R. China

E-mail: 1315513977@qq.com

*Contributed equally

Abbreviations: H. pylori, Helicobacter pylori; OR, odds ratio

Key words: Helicobacter pylori, delayed growth, children, meta-analysis, observational study
$H$. pylori infection was also associated with delayed childhood growth in studies with a $H$. pylori prevalence of $\leq 30 \%$ (OR, 1.71; 95\% CI, 1.31-2.23) or $>30 \%$ but not $>50 \%$ (OR, $1.43 ; 95 \% \mathrm{CI}, 1.10-1.86)$. The association between infection and growth was only statistically significant in the cross-sectional (OR, 1.43; 95\% CI, 1.18-1.73) and case-control (OR, 1.81; 95\% CI, 1.23-2.67) studies. No significant heterogeneity among studies was identified in the present analysis. According to Begg's and Egger's linear regression methods for funnel plots and quantification assessments, no publication bias was identified. The trim and fill method further suggested that $H$. pylori-positive children were prone to delayed linear growth. Therefore, the present study suggested that preventing and detecting $H$. pylori infection in children may be critical to ensure normal growth and development during childhood.

\section{Introduction}

Helicobacter pylori (H. pylori) is a helical, gram-negative micro-aerobic bacterium that colonises the stomach (1). It is the major pathogen associated with gastritis, peptic ulcers and gastric cancer (2-4). Certain $H$. pylori genotypes are risk factors for gastric disease, e.g. the vacuolating toxin A-positive and cytotoxin-associated gene A-positive genotypes (5). $H$. pylori-positive children present with clinical manifestations that vary widely from $H$. pylori-positive adults, including iron deficiency anaemia (6). Furthermore, H. pylori-positive children display no adverse digestive system symptoms, except occasional abdominal pain or duodenal ulcers during late childhood. By contrast, H. pylori-positive adults are susceptible to various clinically significant diseases, including ulcers and cancer of the gastrointestinal system (7-10). It has been reported that successful eradication of $H$. pylori during childhood increases growth and restores serum acylated ghrelin levels in children (11). However, the European and North American Gastroenterology and Nutrition Society does not recommend the detection and treatment of $H$. pylori infection in children due to the low efficacy of the currently recommended $H$. pylori eradication therapy and the lack of broad availability of culture or molecular-based testing (12). Therefore, optimised vaccine strategies and a high-performance first-line treatment based on antimicrobial susceptibility profiles are urgently required for the efficient treatment of $H$. pylori infection in children (12-15). 
A previous study reported a higher percentage of delayed growth, defined according to the World Health Organization (WHO) age-appropriate criteria (2006 edition) $(16,17)$, in children infected with $H$.pylori compared with controls (18), while other studies have reported no effect of $H$. pylori infection on the growth of children (17-19). Thomas et al (19) reported that the effects of $H$. pylori colonisation on malnutrition and delayed growth during early infancy (age, 5-8 years) did not persist into late childhood. Conversely, Perri et al (20) and Fialho et al (21) reported an association between short stature and $H$. pylori infection in older children aged between 8 and 14 years. Furthermore, the effects of $H$. pylori infection on the growth and development of female children have been reported to be associated with puberty (22). Tasar et al (23) reported that $H$. pylori seroprevalence was higher in children with delayed growth compared with the control group. Therefore, the association between the $H$. pylori infection in childhood and delayed growth remains a topic of debate. Routine screening for $H$. pylori in children under 14 years of age is not recommended at present and the Fifth National H. Pylori Infection Consensus Report of China only recommended that children with peptic ulcers should undergo examination for $H$. pylori (24). As an intragastric infection that begins during infancy (25), the effective eradication of $H$. pylori in a paediatric population is critical (13). The meta-analysis performed in the present study comprehensively assessed all available published studies to determine the possible association between $H$. pylori infection and delayed growth during childhood.

\section{Materials and methods}

Literature search. The Meta-analyses of Observational Studies in Epidemiology and Preferred Reporting Items for Systemic Reviews and Meta-Analyses statement guidelines were followed for the literature search in the present study $(26,27)$. PubMed, Exerpta Medica dataBASE, Cochrane Library and the Chinese Biomedical Literature Database were searched for relevant literature using the following terms: 'Helicobacter pylori' [medical subject headings (MeSH) terms] or 'Helicobacter pylori' or ' $H$. pylori', and 'Growth Disorders' (MeSH Terms) or 'disorder, growth' or 'growth disorder', 'stunted growth' or 'growth, stunted' or 'stunting', 'thrive, failure to' or 'Failure to Thrive' (MeSH Terms), or 'growth retardation' or 'growth restriction'. Furthermore, the lists of references all the eligible studies were manually reviewed to identify additional studies.

Inclusion and exclusion criteria. Case-control, cohort and cross-sectional observational studies were included in the present study. All relevant full texts assessing the effect of $H$. pylori infection on delayed growth in children published between January 1st 1994 and January 1st 2019 were included in the present meta-analysis. Case reports, review articles, meta-analyses, duplicate reports, letters to the editor, commentaries, authors' replies and abstracts presented at conferences were excluded from the present study. Articles with insufficient data were also excluded from the present study after two reviewers performed an independent screening of the abstracts and full texts (SW and YD). Any disagreements were resolved by a third reviewer (LP).
Quality assessment. To ensure the quality of the meta-analysis, quality assessments of each of the included articles were performed. Quality evaluation of the case-control and cohort studies was performed using the Newcastle-Ottawa Scale (28). The methodological quality of the cross-sectional studies was evaluated using the 11-item checklist recommended by the Agency for Healthcare Research and Quality that was applied by a previous meta-analysis (29). Higher scores indicated higher quality articles; therefore, articles with a final score of $\geq 7$ points were included in the present study $(28,29)$.

Data extraction. The basic data were extracted from the studies by two reviewers (SW and YD) and included the following: First author, year of publication, country/continent, sample size, age and gender of participants, prevalence of $H$. pylori infection, study design, $H$. pylori detection method, type of delayed growth, definition of delayed growth and adjustment for confounders. Delayed growth was defined according to the WHO age-appropriate criteria (2006 edition) $(16,17)$. The number of children with delayed growth and healthy participants in the $H$. pylori-positive and $H$. pylori-negative groups was also recorded.

Statistical analysis. The potential risk of delayed growth in children infected with $H$. pylori was evaluated using a fixed-effects model to estimate the odds ratio (OR) and 95\% confidence intervals (CI). Statistical heterogeneity was assessed using the $\chi^{2}$ test and $\mathrm{I}^{2}$ index. $\mathrm{P}<0.10$ and $\mathrm{I}^{2}>50 \%$ were considered to indicate statistically significant heterogeneity. $\mathrm{I}^{2}$ values of 0-25, 26-50, 50-75 and $>75 \%$ were considered to indicate no, low, medium and high heterogeneity, respectively (30).

Subgroup analyses were performed based on country/continent, $H$. pylori prevalance, study design, $H$. pylori detection method, type of delayed growth and confounder adjustment. Furthermore, sensitivity analyses were performed to assess whether removing any single study at a later stage affected the primary outcome of the meta-analysis performed in the present study. Begg's and Egger's linear regression were performed to assess publication bias, as evaluated by funnel plots. Finally, the credibility of the results was estimated using the trim and fill method (31). Data analyses were performed using Review Manager (version 5.3; Cochrane) and STATA (version 12.0; StataCorp LP) softwares.

\section{Results}

Baseline characteristics. Of the 488 records initially retrieved, 44 were duplicates and the remaining 444 articles were screened based on titles and abstracts, of which 390 irrelevant studies were excluded. An additional 38 studies were excluded due to insufficient data. Following quality assessment of the remaining 16 observational studies, a total of 15 studies with a quality assessment score of $\geq 7$ (Tables I-III) were included in the present study (Fig. 1), including two cohort $(18,32)$, eight cross-sectional $(20,21,33-38)$ and five case-control (39-43) studies.

The included articles, published between January 1st 1994 and January 1st 2019, comprised 1,371 H. pylori-positive and 2,828 H. pylori-negative children. Delayed growth was reported in $454(33.11 \%) H$. pylori-positive children and 761 

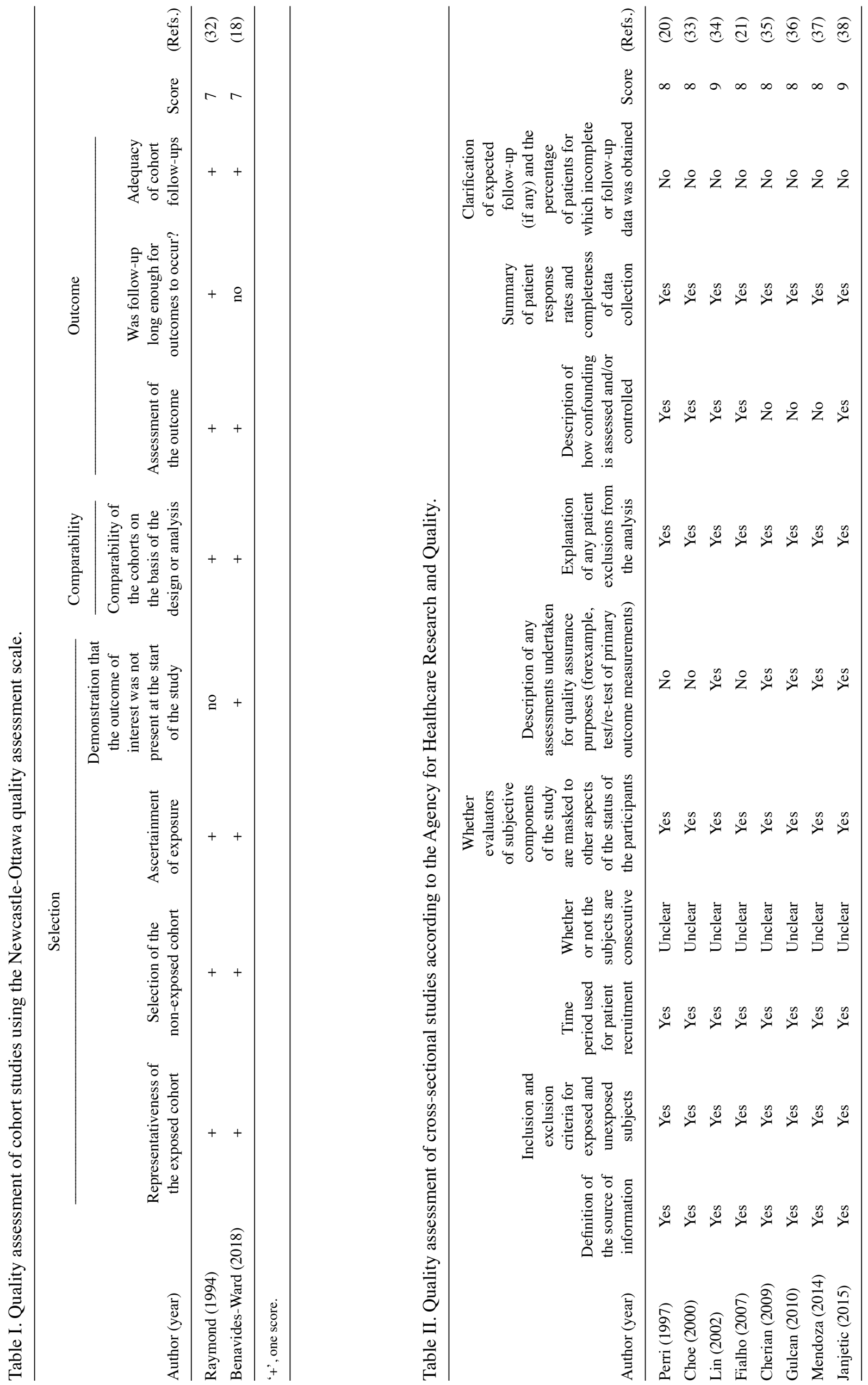
(26.91\%) H. pylori-negative children. The major characteristics of the included studies are presented in Table IV.

Primary outcomes. The prevalence of delayed childhood growth in the $H$. pylori-positive group was significantly increased compared with that in the $H$. pylori-negative group (OR, 1.51; 95\% CI, 1.28-1.78; P<0.00001), with no significant heterogeneity $\left(\chi^{2}=13.34 ; \mathrm{I}^{2}=0 \% ; \mathrm{P}_{\text {Heterogeneity }}=0.50 ;\right.$ Fig. 2$)$. The results indicated that there was a positive association between $H$. pylori infection and delayed childhood growth.

\section{Subgroup analyses}

Country/continent. The 15 observational studies included in the present study consisted of participants from all five continents (Europe, America, Asia, Africa and Oceania). Participants from Europe (OR, 1.61; 95\% CI, 1.11-2.35; $\left.\mathrm{Z}=2.49 ; \mathrm{P}=0.01 ; \mathrm{I}^{2}=0 \% ; \mathrm{P}_{\text {Heterogeneity }}=0.80\right)$, America $(\mathrm{OR}, 1.50$; 95\% CI, 1.16-1.94; $\mathrm{Z}=3.06 ; \mathrm{P}=0.002 ; \mathrm{I}^{2}=2 \% ; \mathrm{P}_{\text {Heterogeneity }}=0.38$ ) and Asia (OR, 1.66; 95\% CI, 1.25-2.20; $\mathrm{Z}=3.49 ; \mathrm{P}=0.0005$; $\left.\mathrm{I}^{2}=0 \% ; \mathrm{P}_{\text {Heterogeneity }}=0.59\right)$ displayed an association between H. pylori infection and delayed childhood growth; however, no association was observed in participants from Africa and Oceania (OR, 0.83; 95\% CI, 0.44-1.56; $\mathrm{Z}=0.58 ; \mathrm{P}=0.56$; $\mathrm{I}^{2}=53 \% ; \mathrm{P}_{\text {Heterogeneity }}=0.14$; Fig. 3).

Prevalence of $H$. pylori infection. The prevalence of $H$. pylori infection varied among the included studies, ranging from 9.17-81.87\% (Table IV). Delayed growth in children among studies with a $H$. pylori prevalence of $\leq 30 \%$ (OR, 1.71; $95 \%$ CI, 1.31-2.23; Z=3.93; $\left.\mathrm{P}<0.0001 ; \mathrm{I}^{2}=0 \% ; \mathrm{P}_{\text {Heterogeneity }}=0.99\right)$ or $>30$ but $\leq 50 \%$ (OR, 1.43; 95\% CI, 1.10-1.86; $\mathrm{Z}=2.64 ; \mathrm{P}=0.008$; $\left.\mathrm{I}^{2}=34 \% ; \mathrm{P}_{\text {Heterogeneity }}=0.21\right)$ was associated with $H$. pylori infection, with no significant heterogeneity $\left(\chi^{2}=1.38 ; \mathrm{I}^{2}=0 \%\right.$; $\left.\mathrm{P}_{\text {Heterogeneity }}=0.50\right)$. However, there was no association between delayed growth and $H$. pylori infection in studies with a H. pylori prevalence prevalence of $>50 \%(\mathrm{OR}, 1.36 ; 95 \% \mathrm{CI}$, 0.97-1.90; Z=1.78; P=0.08; Fig. 4).

Study design. Of the three types of observational studies included in the present analysis, cross-sectional (OR, 1.43; 95\% CI, 1.18-1.73; $\mathrm{Z}=3.68 ; \mathrm{P}=0.0002)$ and case-control $(\mathrm{OR}$, 1.81; 95\% CI, 1.23-2.67; $\mathrm{Z}=3.00 ; \mathrm{P}=0.003)$ studies displayed an association between $H$. pylori infection and delayed childhood growth. Cohort studies did not display any association between the two factors $(\mathrm{OR}, 1.64 ; 95 \% \mathrm{CI}, 0.89-3.03 ; \mathrm{Z}=1.58$; $\mathrm{P}=0.11)$. The heterogeneity among the three subgroups was not significant $\left(\chi^{2}=1.24 ; \mathrm{I}^{2}=0 \% ; \mathrm{P}_{\text {Heterogeneity }}=0.54 ;\right.$ Fig. 5).

H.pylori detection method. In the studies using ${ }^{13} \mathrm{C}$-urea breath tests (UBTs; OR, 1.72; 95\% CI, 1.22-2.40; $\mathrm{Z}=3.14 ; \mathrm{P}=0.002$; $\left.\mathrm{I}^{2}=0 \% ; \mathrm{P}_{\text {Heterogeneity }}=0.86\right)$ and serum $\mathrm{IgG}$ antibodies targeted against $H$. pylori (OR, 1.81; 95\% CI, 1.35-2.44; $\mathrm{Z}=3.97$; $\left.\mathrm{P}<0.0001 ; \mathrm{I}^{2}=0 \% ; \mathrm{P}_{\text {Heterogeneity }}=0.89\right)$ detection methods, an association between $H$. pylori infection and delayed childhood growth was detected. However, the studies using other detection methods did not display any association, including the rapid urease test (OR, 1.32; 95\% CI, 0.90-1.94; $\mathrm{Z}=1.43$; $\left.\mathrm{P}=0.15 ; \mathrm{I}^{2}=0 \% ; \mathrm{P}_{\text {Heterogeneity }}=0.88\right)$, monoclonal faecal antigen enzyme immunoassay testing (OR, 0.55; 95\% CI, 0.24-1.25; $\mathrm{Z}=1.44 ; \mathrm{P}=0.15)$, $\mathrm{PCR}$ amplification of the $23 \mathrm{~S}$ ribosomal 


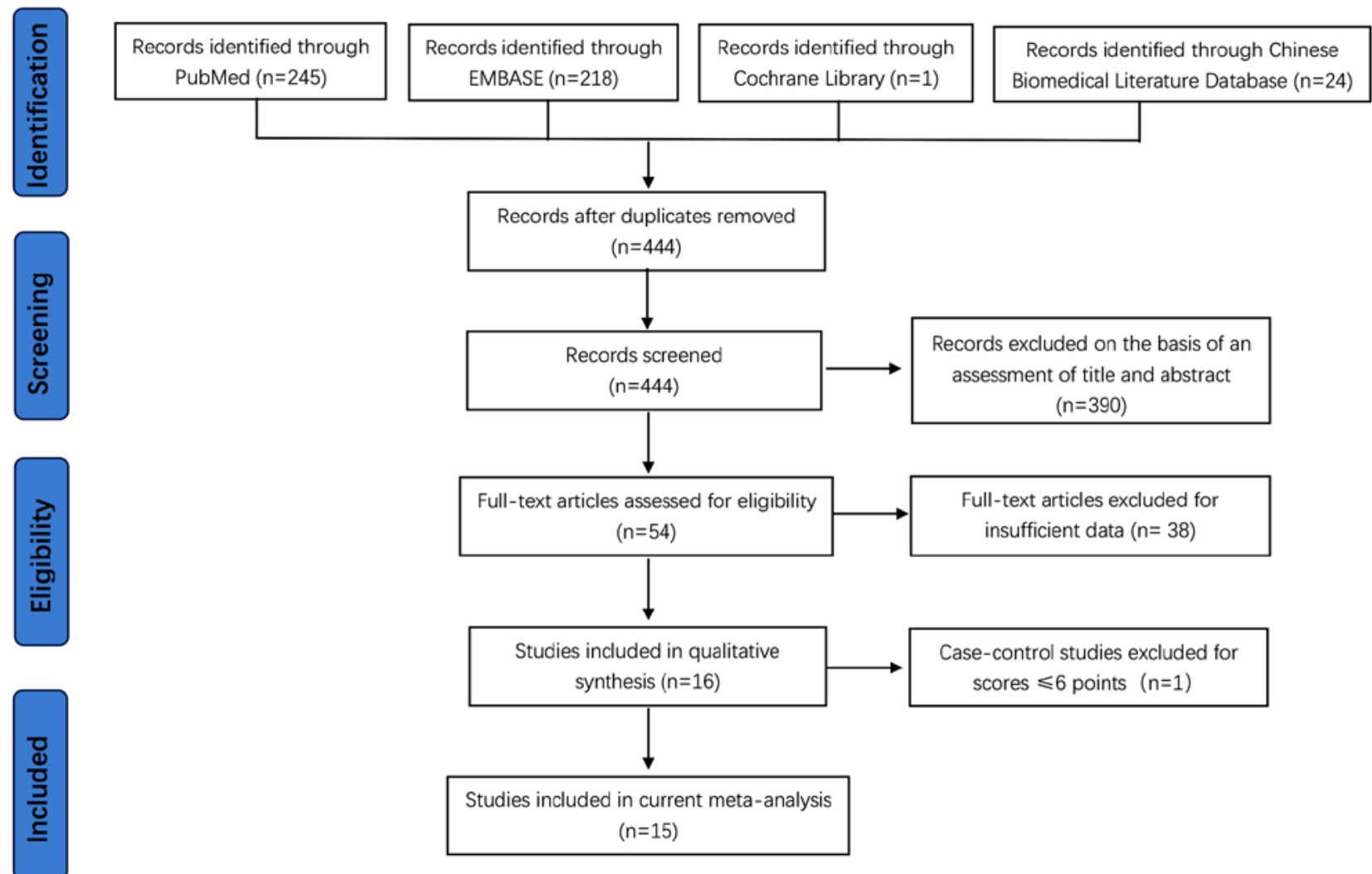

Figure 1. Flow diagram of the literature search conducted in the present study. EMBASE, Exerpta Medica data BASE.

RNA gene (OR, 3.08; 95\% CI, 0.98-9.67; $\mathrm{Z}=1.92 ; \mathrm{P}=0.05)$ or at least one of three positive examinations $\left[{ }^{13} \mathrm{C}\right.$-UBT, antibodies to whole-cell $H$. pylori and cytotoxin-associated gene A (CagA) antigens; OR, 1.24; 95\% CI, 0.86-1.79; Z=1.17; $\mathrm{P}=0.24$; Fig. 6].

Measures of delayed growth. H. pylori infection was associated with the incidence of delayed growth when the primary outcome was height (OR, 1.63; 95\% CI, 1.32-2.00; $\mathrm{Z}=4.57$; $\left.\mathrm{P}<0.00001 ; \mathrm{I}^{2}=0 \% ; \mathrm{P}_{\text {Heterogeneity }}=0.72\right)$, which suggested that delayed linear growth was associated with $H$. pylori infection. H. pylori infection was also associated with delayed growth when height and weight were collectively analysed as the primary outcome (OR, 1.33; 95\% CI, 1.00-1.75; $\mathrm{Z}=1.99$; $\left.\mathrm{P}=0.05 ; \mathrm{I}^{2}=33 \% ; \mathrm{P}_{\text {Heterogeneity }}=0.19\right)$. No association was observed when the height, weight and mid-upper arm circumference were collectively analysed as the primary outcome (OR, 1.39; 95\% CI, 0.52-3.74; $\mathrm{Z}=0.66 ; \mathrm{P}=0.51)$ and no heterogeneity was identified among these subgroup analyses $\left(\chi^{2}=1.34 ; \mathrm{I}^{2}=0 \%\right.$; $\mathrm{P}_{\text {Heterogeneity }}=0.51$; Fig. 7).

Confounder adjustment. Subgroup analyses were performed based on confounder adjustment; four studies were adjusted for potential confounders and the pooled OR was $1.32(95 \%$ CI, 1.02-1.70; $\mathrm{Z}=2.12 ; \mathrm{P}=0.03)$ with no significant heterogeneity $\left(\mathrm{I}^{2}=52 \% ; \mathrm{P}_{\text {Heterogeneity }}=0.10\right)$. The pooled unadjusted $\mathrm{OR}$ value was 1.67 (95\% CI, 1.34-2.07; $\mathrm{Z}=4.63$; $\mathrm{P}<0.00001)$ for the remaining 11 studies, with no significant heterogeneity $\left(\mathrm{I}^{2}=0 \% ; \mathrm{P}_{\text {Heterogeneity }}=0.88\right)$. Therefore, the results suggested that $H$. pylori infection was associated with delayed childhood growth, regardless of the adjustment for potential confounders (Fig. 8).

Sensitivity analysis. Following the omission of one study at a time, the pooled OR values of the remaining studies ranged from 1.47-1.58 with insignificant heterogeneity $\left(\mathrm{I}^{2}=0-2 \%\right.$; $\mathrm{P}_{\text {Heterogeneity }}>0.10$ ), and the upper and lower thresholds of the $95 \%$ CI were $>1$, indicating that none of the results were significantly altered by the removal of one article from the meta-analysis $\left(\mathrm{P}_{\text {Remainders' effect }}<0.0001\right.$; Table V; Fig. 9).

Publication bias. The funnel plot analysis suggested that there may be a certain amount of publication bias, since the included studies were not distributed completely symmetrically in the funnel plots (Fig. 10A). To investigate the potential publication bias, the included studies were evaluated using the Begg's and Egger's linear regression tests. No significant publication bias was detected using Begg's $(P>|z|=0.113)$ or Egger's $(P>|t|=0.257)$ linear regression analyses (Fig. 10B). Furthermore, adjustment of the funnel plots by the trim and fill method did not alter the results and a statistically significant association between $H$. pylori infection and delayed childhood growth was still observed $(\mathrm{P}<0.0001)$, indicating that the results were stable and credible (Fig. 10C).

\section{Discussion}

To the best of our knowledge, the present study was the first to investigate the association between $H$. pylori infection and delayed childhood growth. Following searching and 


\begin{tabular}{|c|c|c|c|c|c|c|c|c|c|}
\hline $\begin{array}{l}\dot{\mathscr{\Xi}} \\
\ddot{\mathscr{E}}\end{array}$ & ત્ర & ટ્d & ๙ิ) & $\stackrel{\text { P }}{\text { f }}$ & $\widehat{\mathscr{C}}$ & $\widehat{\mathcal{J}}$ & $\stackrel{\overparen{J}}{\mathscr{I}}$ & 苞 & $\widehat{\widehat{d}}$ \\
\hline 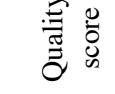 & $r$ & $\infty$ & $\infty$ & $r$ & $\infty$ & $\infty$ & $r$ & $a$ & $\infty$ \\
\hline 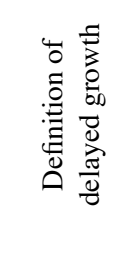 & 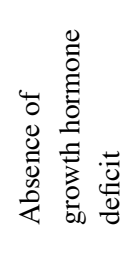 & 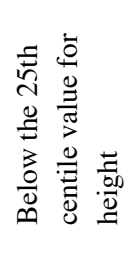 & 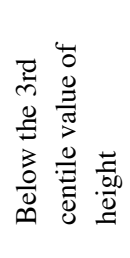 & 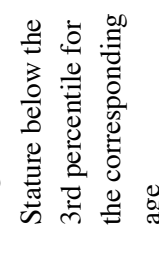 & 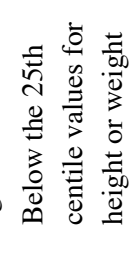 & 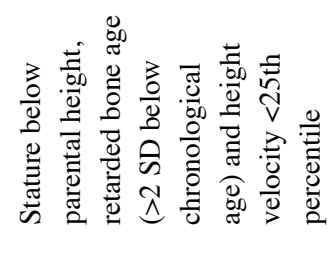 & 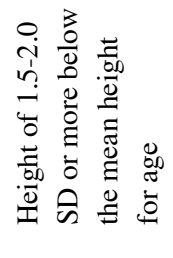 & 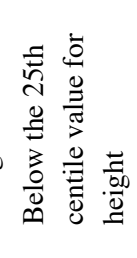 & 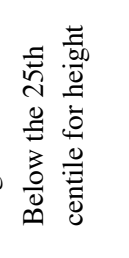 \\
\hline 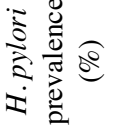 & $\begin{array}{l}\text { gे } \\
\text { in }\end{array}$ & $\begin{array}{l}\text { oे. } \\
\text { ì }\end{array}$ & $\stackrel{\hat{\sigma}}{\underline{b}}$ & $\stackrel{7}{a}$ & 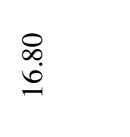 & $\begin{array}{l}8 \\
8 \\
i n\end{array}$ & $\stackrel{\overbrace{}}{\stackrel{0}{0}}$ & $\begin{array}{l}\infty \\
\stackrel{\infty}{\varrho}\end{array}$ & $\begin{array}{l}\vec{\infty} \\
\text { in } \\
i n\end{array}$ \\
\hline 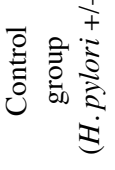 & $\frac{n}{n}$ & $\stackrel{\stackrel{v}{Z}}{\rightrightarrows}$ & 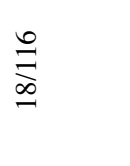 & $\frac{a}{0}$ & 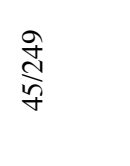 & 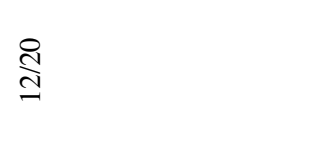 & $\frac{f}{m}$ & 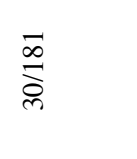 & $\frac{\infty}{i n}$ \\
\hline 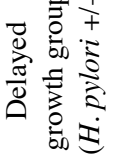 & 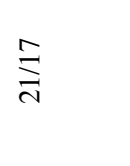 & $\frac{m}{\infty}$ & 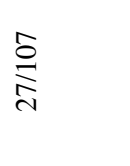 & $\stackrel{\infty}{\stackrel{\infty}{\infty}}$ & $\begin{array}{l}\hat{\beta} \\
\stackrel{\infty}{-}\end{array}$ & $\stackrel{\infty}{\varrho}$ & $\tilde{\omega}$ & $\underset{\mathrm{f}}{\overrightarrow{\mathrm{f}}}$ & 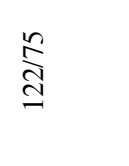 \\
\hline 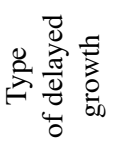 & 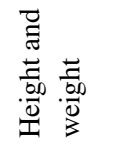 & $\begin{array}{l}\frac{7}{\overrightarrow{0}} \\
\frac{.00}{0.0} \\
\frac{1}{1}\end{array}$ & 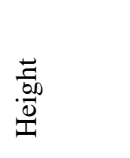 & $\begin{array}{l}\frac{\overrightarrow{0}}{.00} \\
\frac{.00}{0} \\
\vec{I}\end{array}$ & 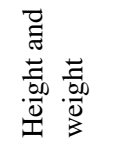 & 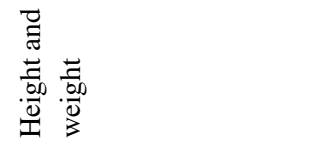 & 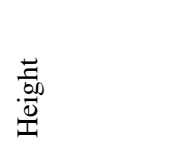 & 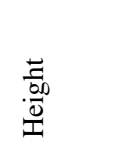 & 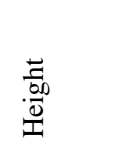 \\
\hline 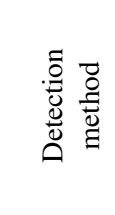 & 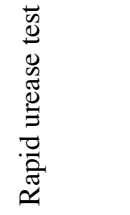 & 苞 & 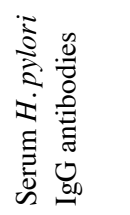 & 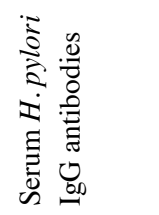 & 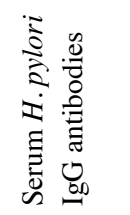 & 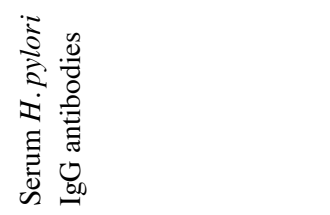 & 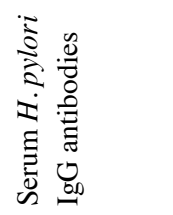 & 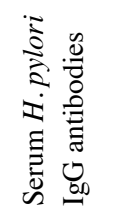 & 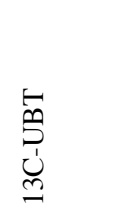 \\
\hline 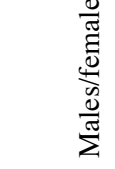 & $\underset{z}{\varangle}$ & $\overleftrightarrow{Z}$ & 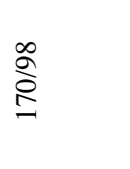 & $\frac{8}{8}$ & $\stackrel{?}{\stackrel{2}{n}}$ & $\overleftrightarrow{\Delta}$ & $\frac{\bar{m}}{i}$ & 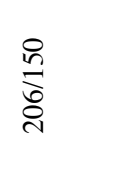 & 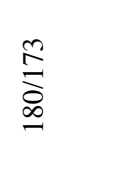 \\
\hline 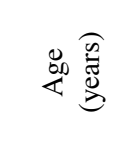 & $\frac{0}{0}$ & $\frac{\vec{m}}{m}$ & $\frac{m}{n}$ & $\frac{0}{i}$ & $\frac{n}{0}$ & 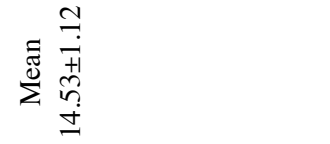 & $\stackrel{0}{I}$ & 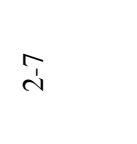 & $\stackrel{+}{n}$ \\
\hline 总: & $\underline{n}$ & $\stackrel{0}{\sim}$ & i̊ i & $\stackrel{\infty}{m}$ & $\stackrel{n}{m}$ & in & $\infty$ & ஜे & $\tilde{n}$ \\
\hline 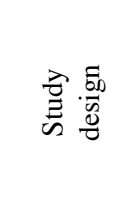 & $\begin{array}{l}5 \\
\overline{0} \\
0\end{array}$ & 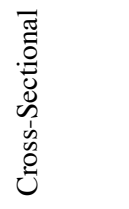 & 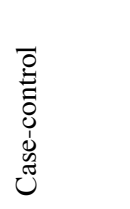 & 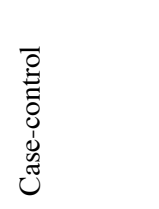 & 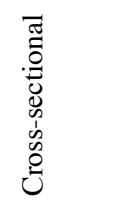 & 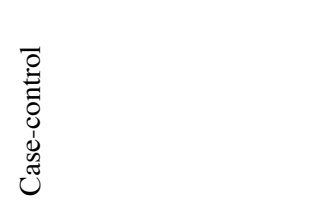 & 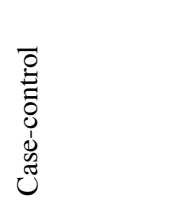 & 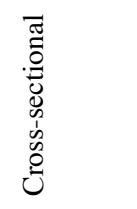 & 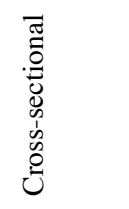 \\
\hline 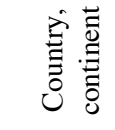 & 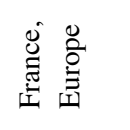 & 产䓌 & 忞总 & 﨎 & 离 & 离 & 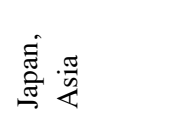 & 窇 & 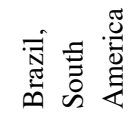 \\
\hline 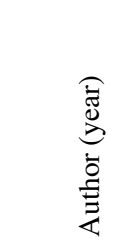 & 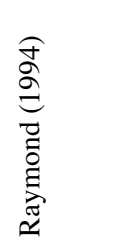 & 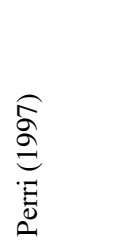 & 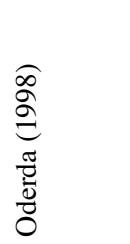 & 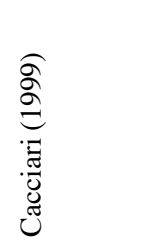 & 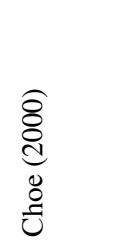 & 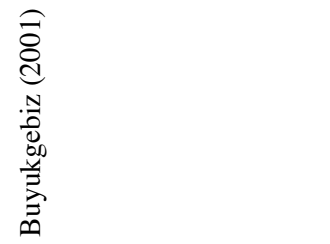 & 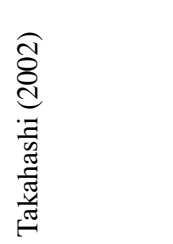 & $\begin{array}{l}\widehat{\widehat{d}} \\
\text { d્ } \\
. \Xi\end{array}$ & 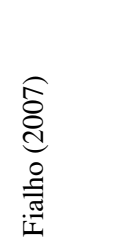 \\
\hline
\end{tabular}




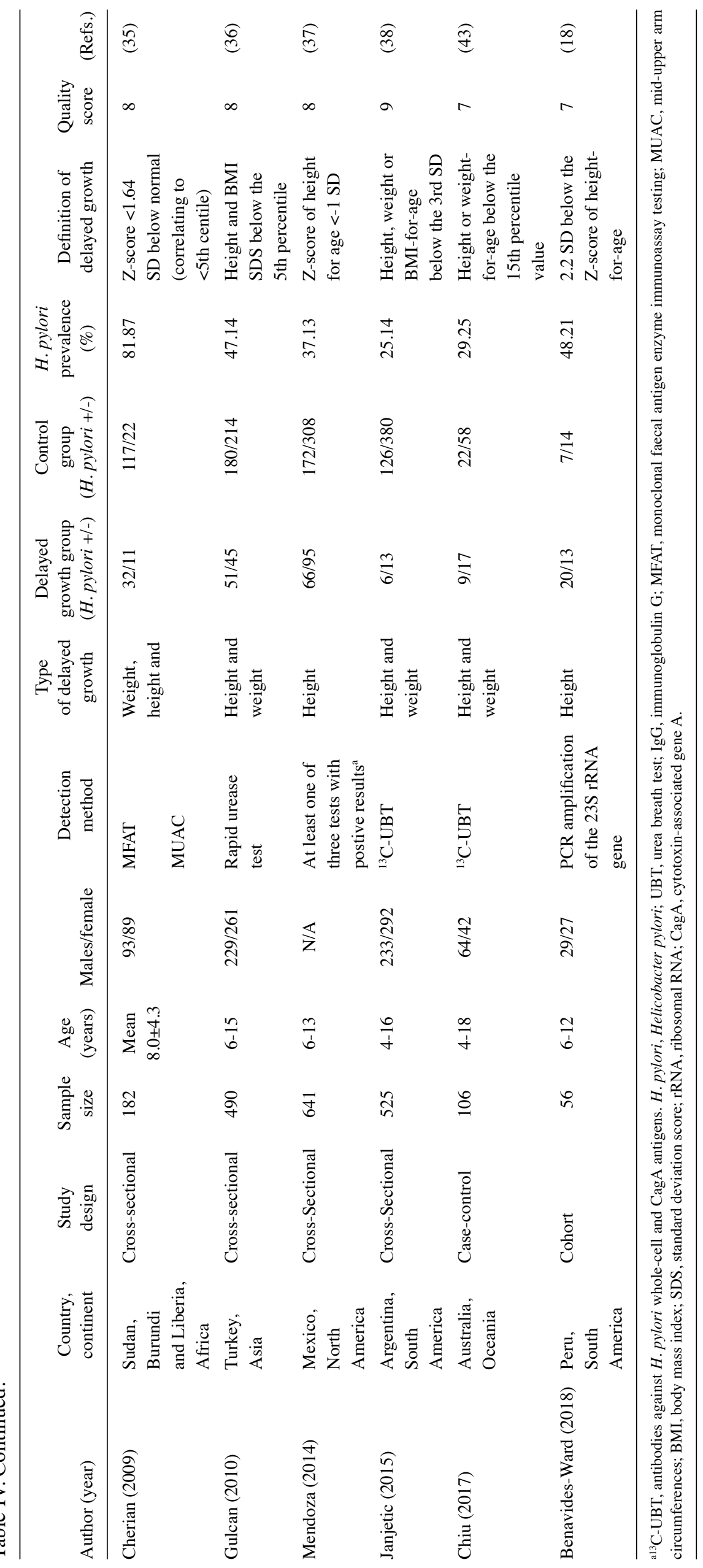




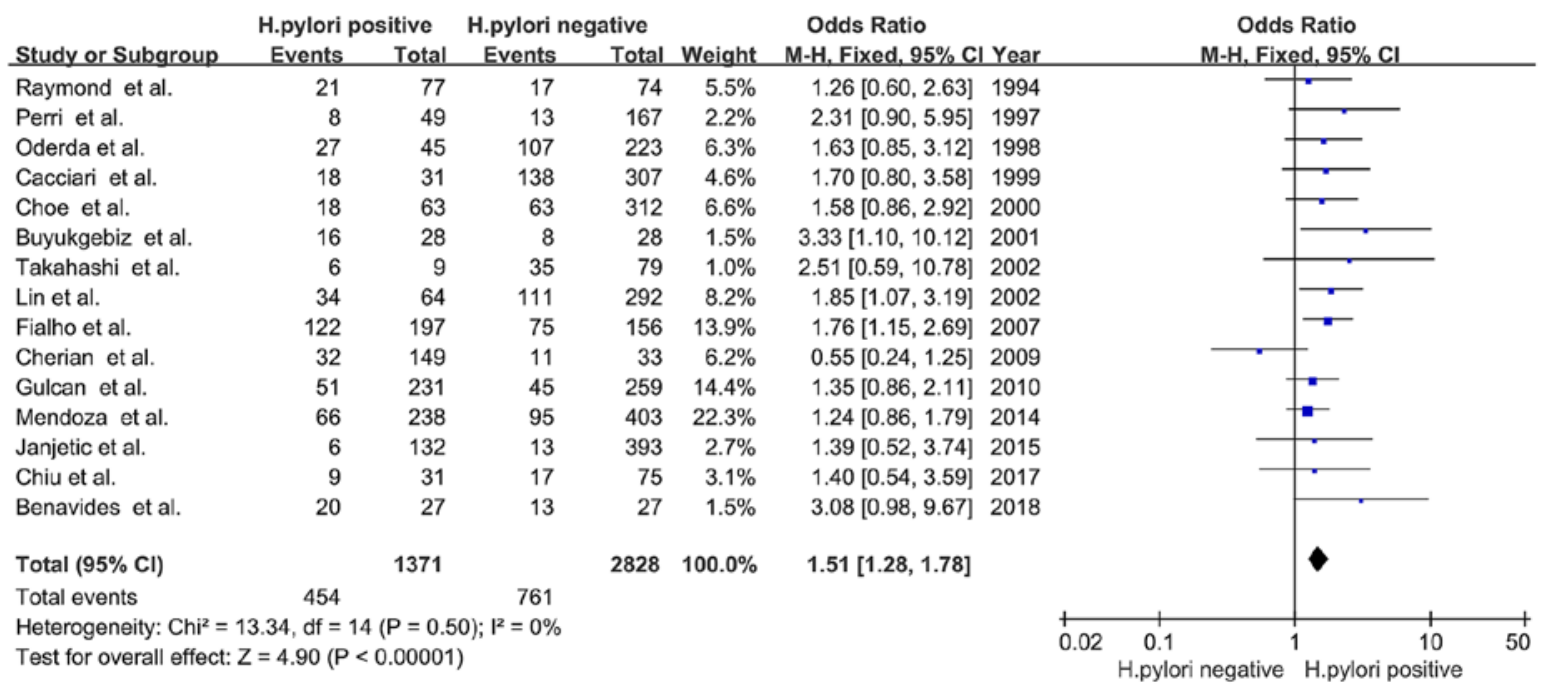

Figure 2. Forest plots of the meta-analysis of the association between $H$. pylori infection and delayed childhood growth. The blue squares represent the OR value, whilst black diamonds represent the combined results of the included studies. H. pylori, Helicobacter pylori; df, degrees of freedom; M-H, Mantel-Haentzel.

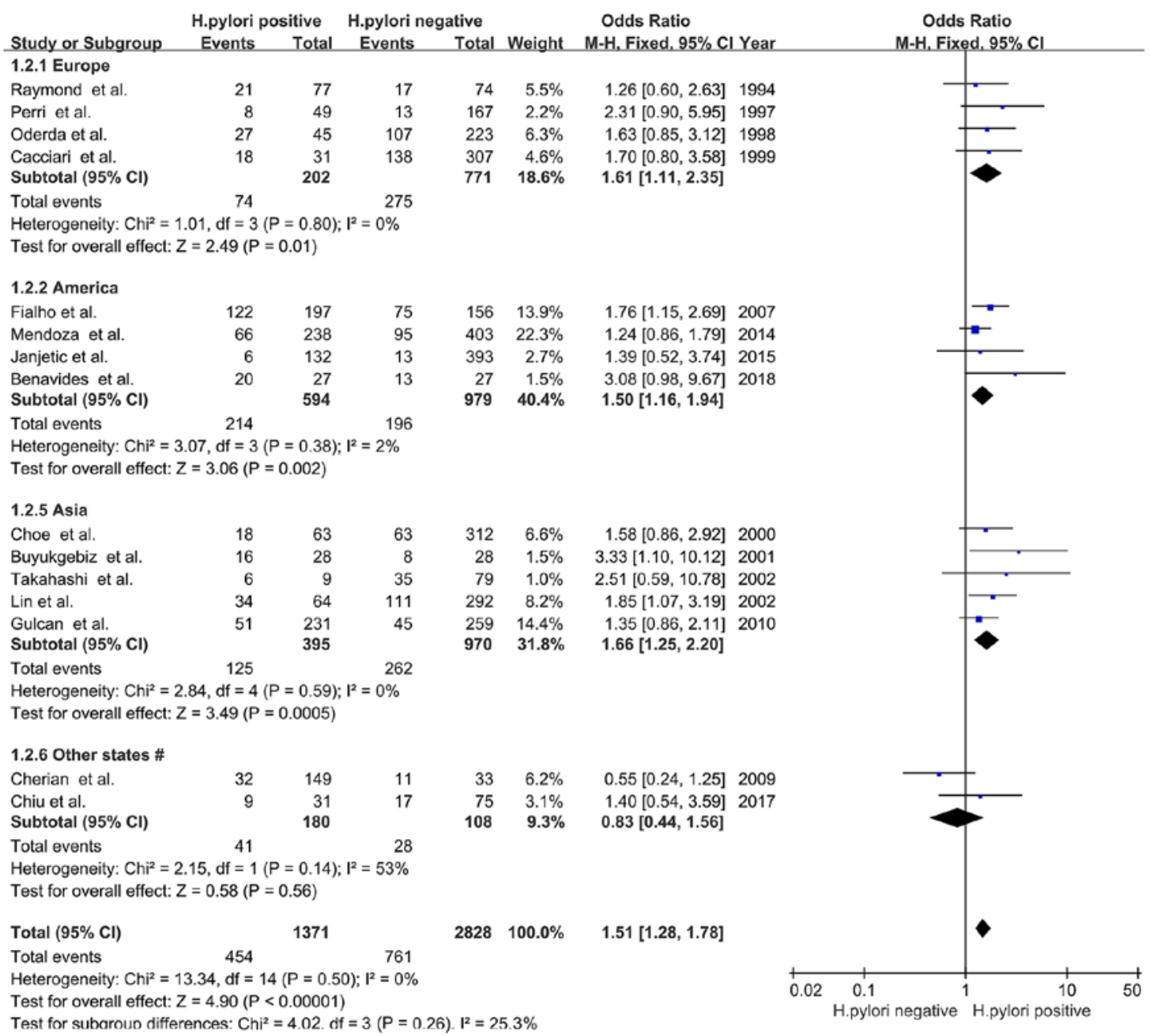

Figure 3. Forest plots of subgroup analysis based on country/continent. The blue squares represent the OR value, whilst black diamonds represent the combined results of the included studies. \#, Africa and Oceania; H. pylori, Helicobacter pylori; df, degrees of freedom; M-H, Mantel-Haentzel.

screening, low-quality studies (23) were excluded and fifteen observational studies involving 4,199 children were used for the meta-analysis performed in the present study. The likelihood of delayed childhood growth was significantly 


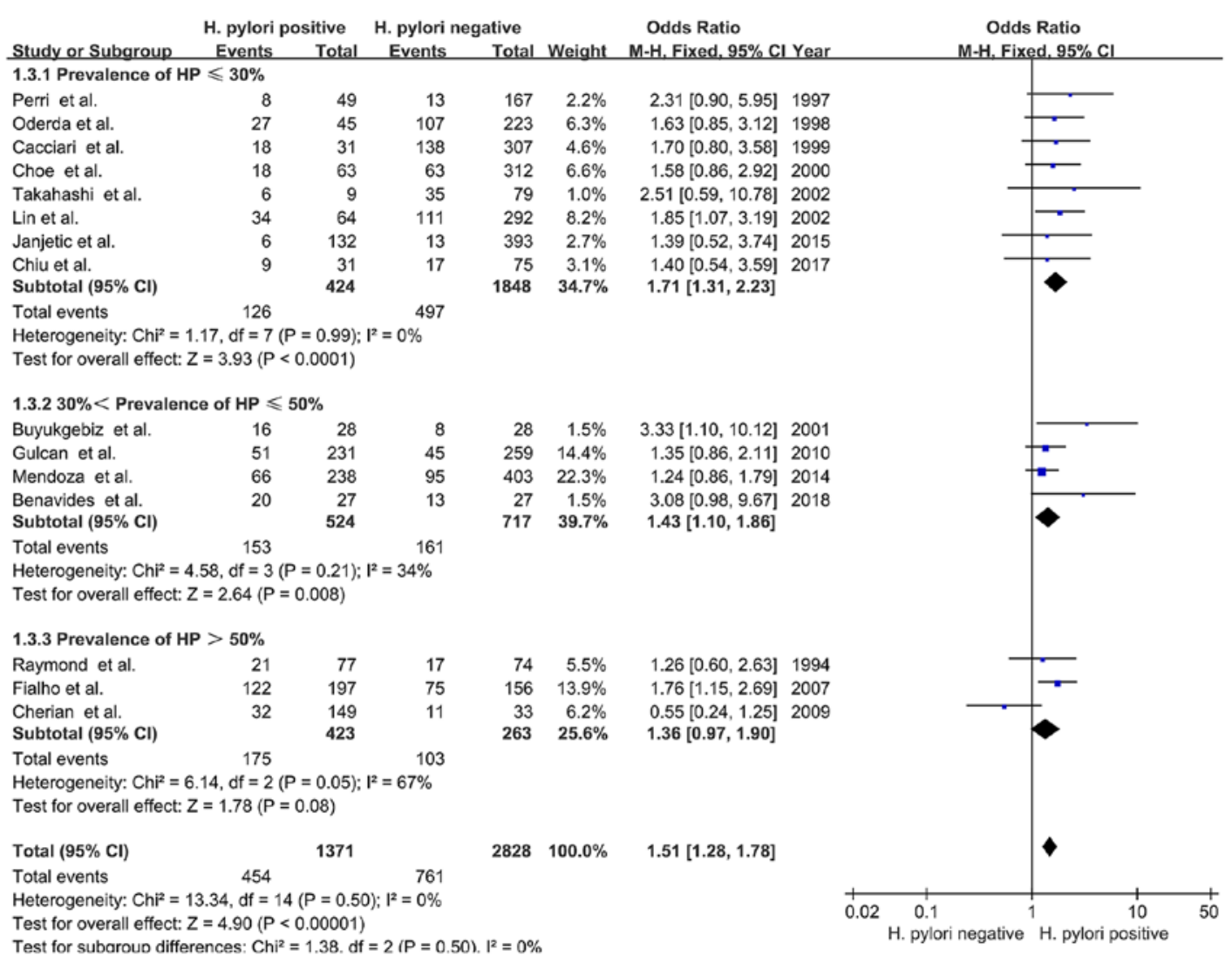

Figure 4. Forest plots of subgroup analysis based on prevalence of $H$. pylori. The blue squares represent the OR value, whilst black diamonds represent the combined results of the included studies. H. pylori, Helicobacter pylori; df, degrees of freedom; M-H, Mantel-Haentzel.

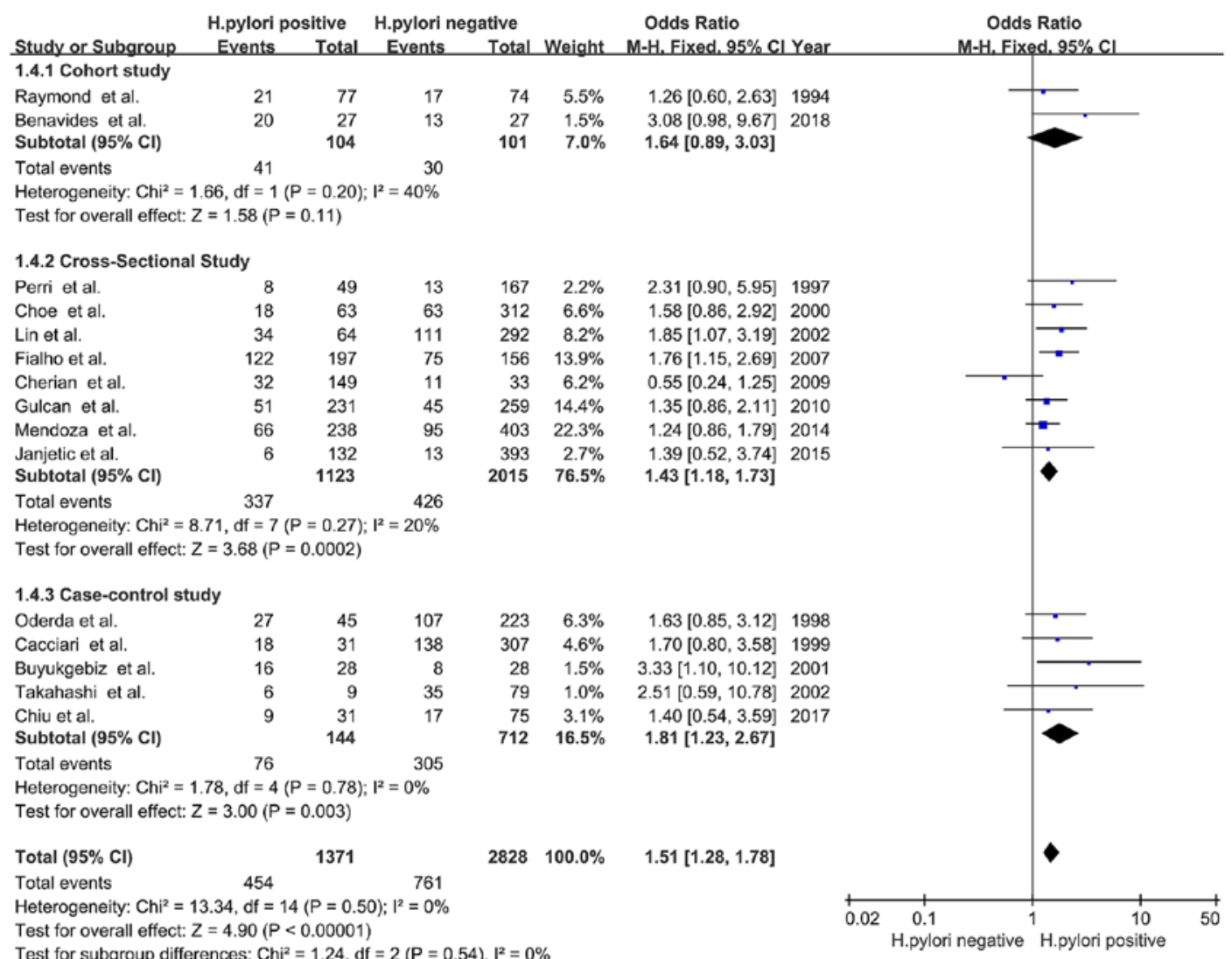

Figure 5. Forest plots of subgroup analysis based on study design. The blue squares represent the OR value, whilst black diamonds represent the combined results of the included studies. H. pylori, Helicobacter pylori; df, degrees of freedom; M-H, Mantel-Haentzel. 


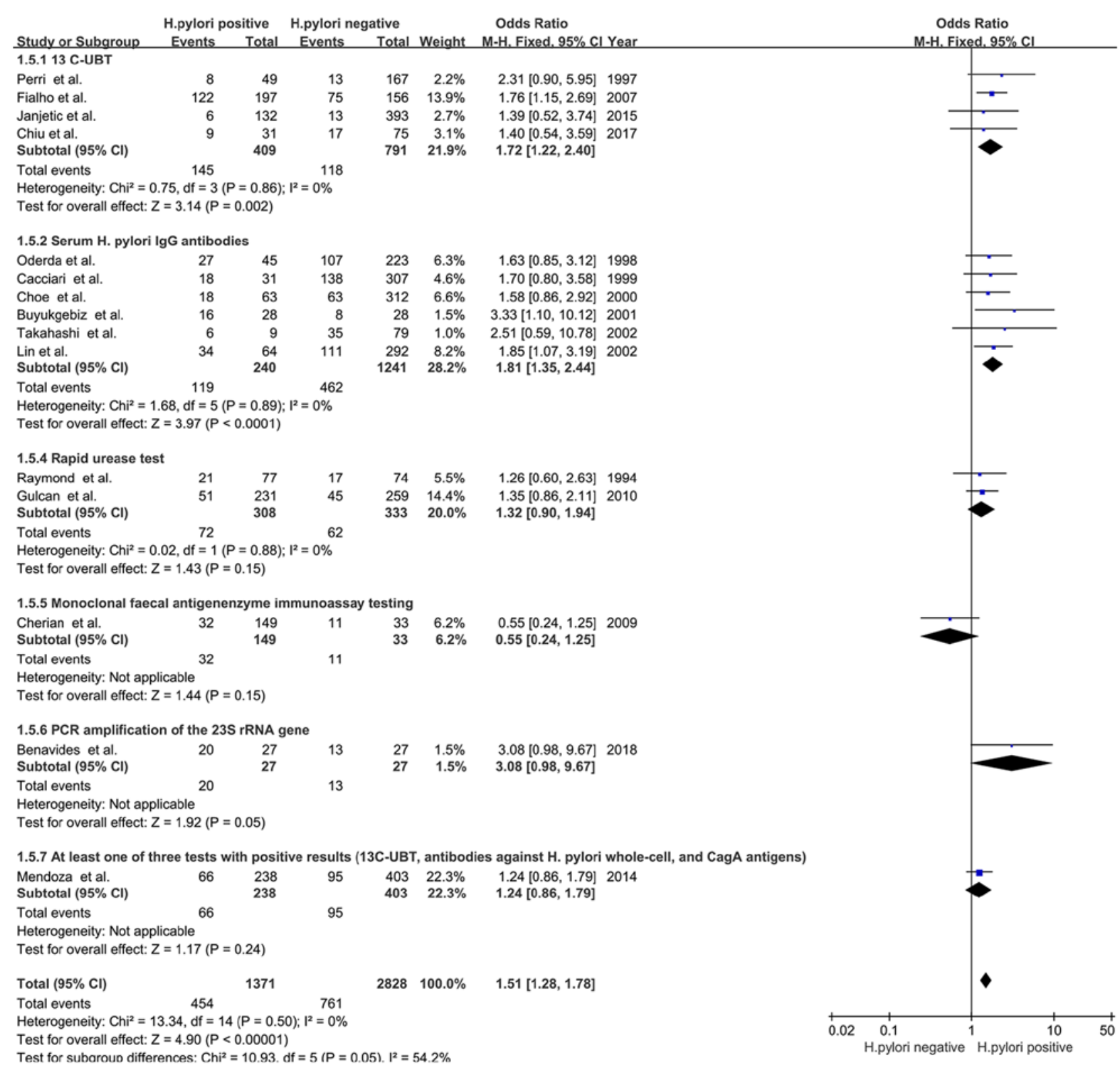

Figure 6. Forest plots of subgroup analysis based on H. pylori detection method. The blue squares represent the OR value, whilst black diamonds represent the combined results of the included studies. H. pylori, Helicobacter pylori; df, degrees of freedom; M-H, Mantel-Haentzel; UBT, urea breath test; $\mathrm{IgG}$, immunoglobulin $\mathrm{G}$; rRNA, ribosomal RNA; CagA, cytotoxin-associated gene A.

increased in $H$. pylori-positive children compared with that in $H$. pylori-negative children. A series of further analyses indicated that the results of the present study were credible and stable.

Delayed growth is the most significant nutritional problem worldwide, which leads to long-term effects and may occur in utero (44). The present study suggested that $H$. pylori infection may be a potential risk factor for delayed childhood growth, particularly linear growth; however, the specific underlying mechanisms require further investigation. It remains elusive whether delayed childhood growth is due to the direct effects of $H$. pylori-induced inflammation or indirect effects of the infection, e.g. anorexia, abdominal pain, malabsorption or diarrhoea. Therefore, delayed growth may be due to direct as well as indirect effects of $H$. pylori infection (45). The clinical outcomes of $H$. pylori infection are affected by a number of factors, including virulence, the host gastric mucosa and the environment (46).

Clinical symptoms of $H$.pylori infection vary between children and adults, with a lower incidence of gastroduodenal ulcers, gastric adenocarcinoma and mucosa-associated lymphoid tissue lymphoma in children $(47,48)$. H. pylori-induced gastric inflammation is less severe in children compared with that in adults, due to the decreased gastric type 17 T-helper cell/interleukin-17 response in children, which is associated with increased activity of the mucosal regulatory T cells (48). Therefore, the extra-digestive manifestations of $H$. pylori colonisation in children, including iron deficiency anaemia (6), cognitive function (49), type I diabetes mellitus (50), Henoch-Schonlein purpura (51) and delayed growth, require constant medical attention. H. pylori infection has been reported in numerous studies as a risk factor for delayed childhood growth $(18,20,21,23,34,37,41)$, 


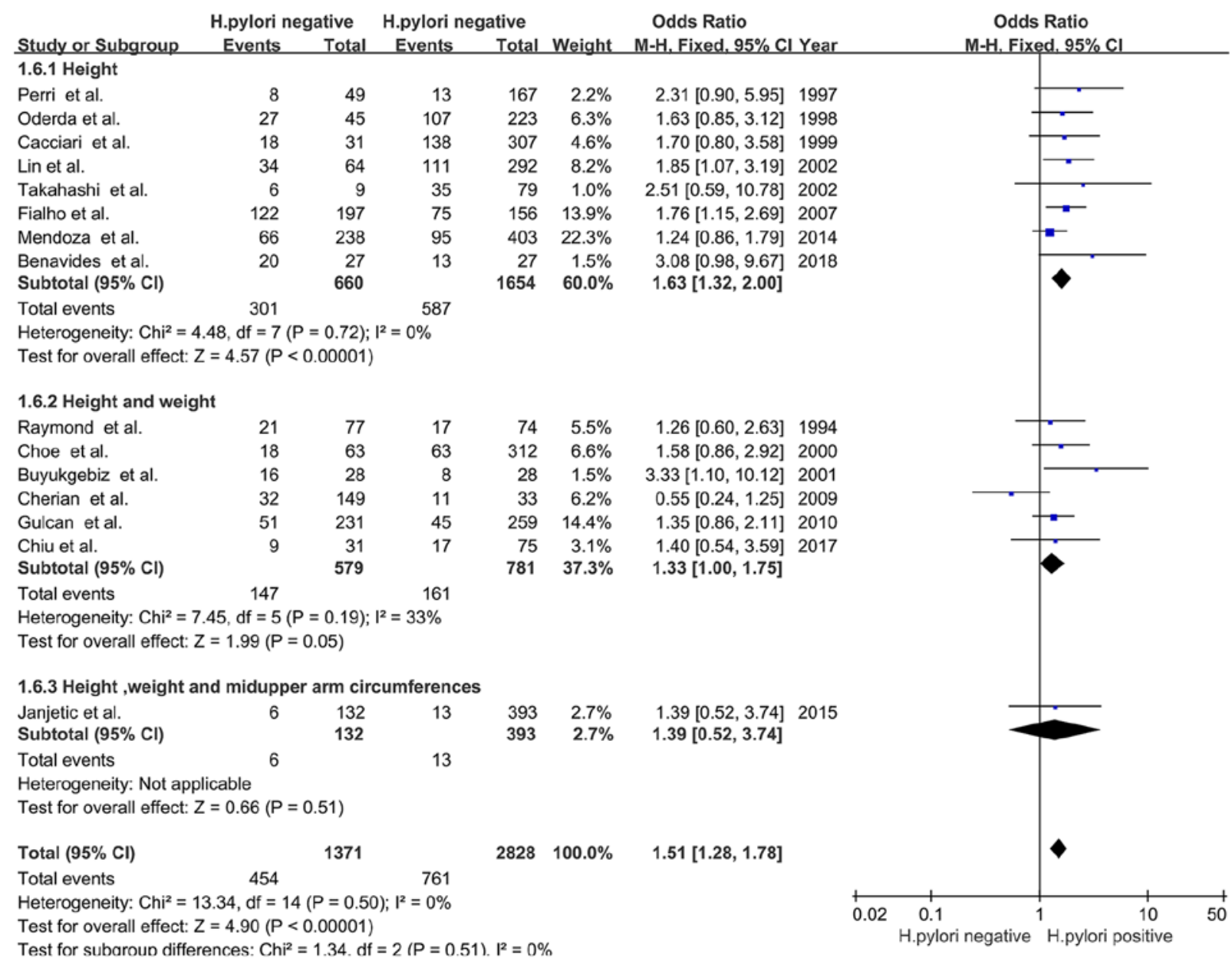

Figure 7. Forest plots of subgroup analysis based on types of delayed growth. H. pylori, Helicobacter pylori; df, degrees of freedom; M-H, Mantel-Haentzel.

and of note, Yang et al (11) reported that eradication of H.pylori infection promotes growth in children. A retrospective study indicated that the prevalence of childhood gastric cancer may be reduced by decreasing the prevalence of $H$. pylori infection in adolescents and children (15). However, Dehghani et al (52) suggested that $H$. pylori infection did not affect the calculated standard deviation score (height and body mass index) (52). Cherian et al (35), Janjetic et al (38), Chiu et al (43) and Choe et al (33) reported that childhood growth and puberty are affected by iron deficiency anaemia and $H$. pylori infection, rather than $H$. pylori infection alone. Ortiz-Princz et al (46) revealed that early identification and intervention of $H$. pylori infection during childhood prevents further serious complications during adulthood, which is consistent with the results of the present study.

In the present meta-analysis, the subgroup analyses demonstrated an association between $H$. pylori infection and childhood growth in European, American and Asian subjects, but not in African and Oceanian subjects. The association was also identified in studies with a $\mathrm{H}$. pylori prevalence of $\leq 50 \%$, but not in studies with a $H$. pylori prevalence of $>50 \%$. A potential explanation for these differences may be different H. pylori prevalence, as well as different environmental and nutritional factors in different countries and regions. Other factors associated with the high prevalence of $H$. pylori infection and delayed growth in children are linked to the socio-economic development of the population, which is associated with limited health care resources, insufficient nutrition and a poor living environment, which may have influenced the results obtained (53-57).

Furthermore, only cross-sectional and case-control studies indicated that $H$. pylori infection was associated with delayed growth in children. An improvement in diet and living conditions during the long-term follow-up of cohort studies may impact the outcome. In addition, the ${ }^{13} \mathrm{C}$-UBT and serum IgG antibodies targeted against $H$. pylori detection methods suggested that $H$. pylori infection was associated with delayed growth in children. Although ${ }^{13} \mathrm{C}-\mathrm{UBT}$ effectively detects $H$. pylori infection (58), the detection method has a high rate of false-positives in children aged $<6$ years (59). A relevant study reported that detection of $H$. pylori using serum $\operatorname{IgG}$ antibodies displayed $88.4 \%$ sensitivity and $93.4 \%$ specificity compared with histology (60). Anti-H. pylori IgG and IgA antibody titers are higher in children with CagA-positive sera regardless of their age. Therefore, serum IgG or IgA antibodies are recommended for the detection of $H$. pylori in asymptomatic children aged $<6$ years (61). Non-invasive screening methods may be used for children aged $>6$ years based on different situations, while children with adverse gastrointestinal symptoms, including peptic ulcers and dyspepsia, should be evaluated by upper gastrointestinal endoscopy for the diagnosis of associated pathology (62). Consistent with the conclusion proposed 


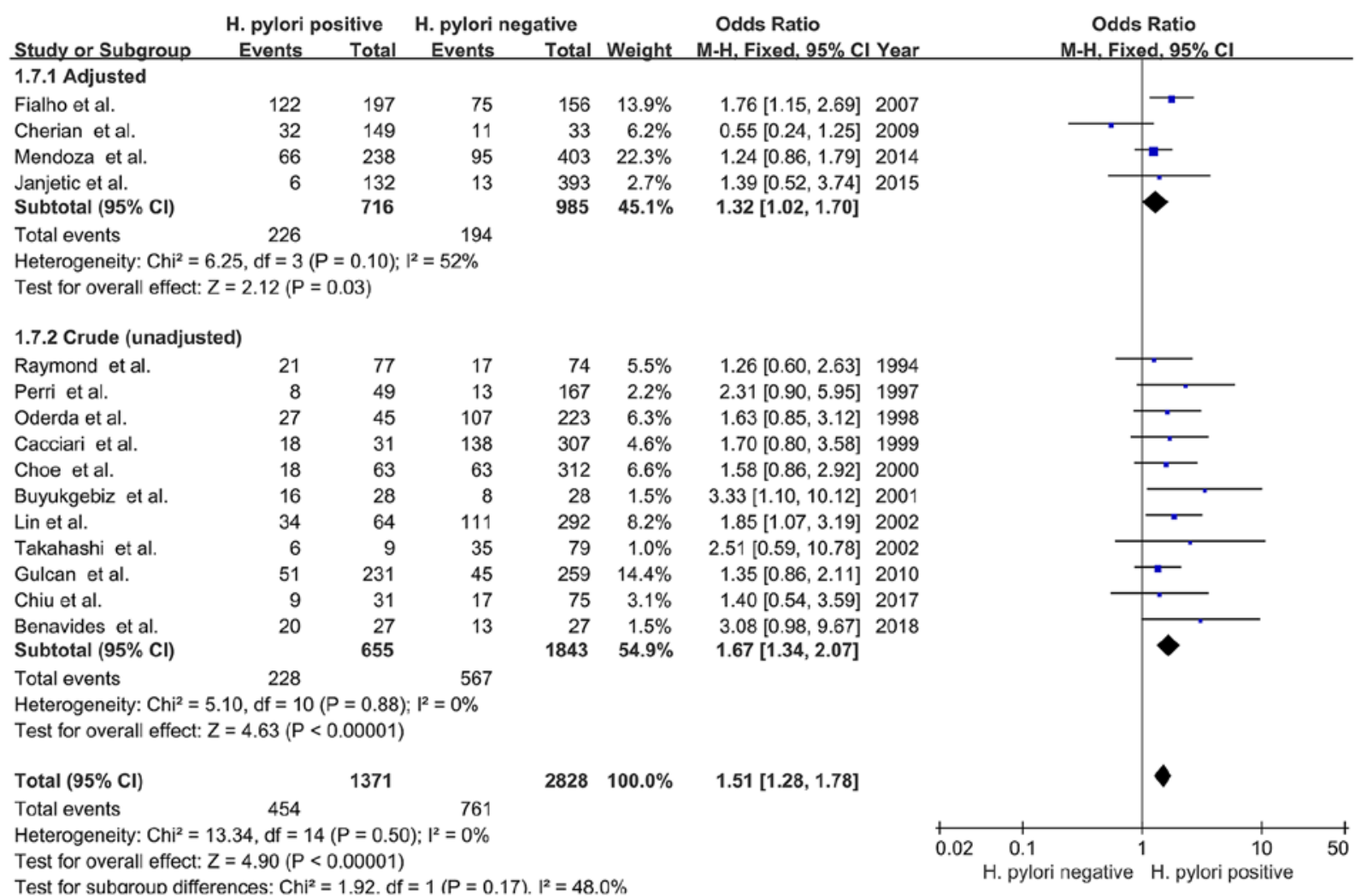

Figure 8. Forest plots of subgroup analysis based on confounders adjustment. The blue squares represent the OR value, whilst black diamonds represent the combined results of the included studies. H. pylori, Helicobacter pylori; df, degrees of freedom; M-H, Mantel-Haentzel.

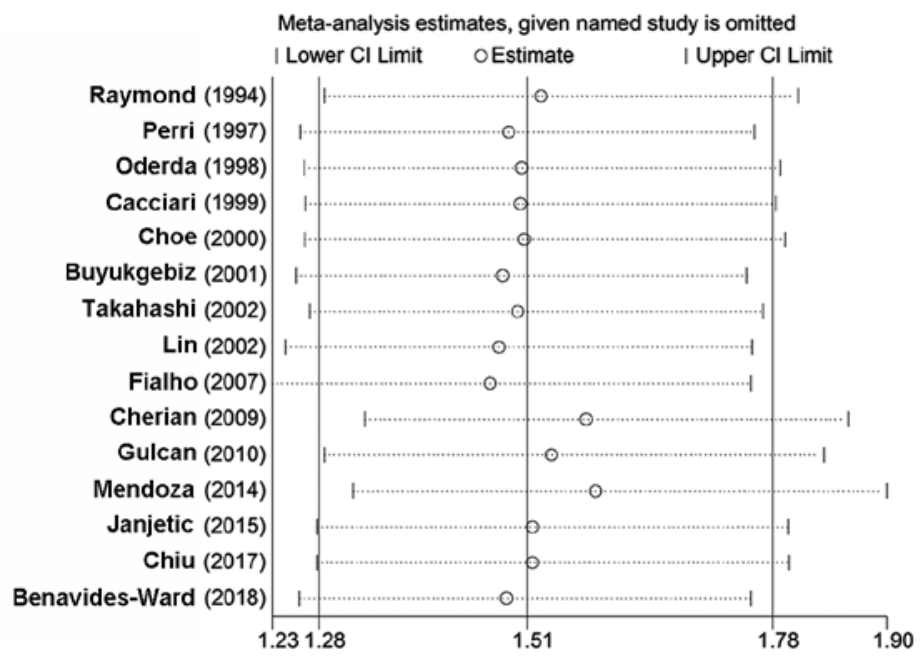

Figure 9. Sensitivity analysis of the association between Helicobacter pylori infection and delayed childhood growth.

by Chilengi et al (44), the subgroup analysis performed in the present study suggested that there was a significant association between $H$. pylori infection and delayed linear childhood growth, regardless of whether or not the potential confounders had been adjusted.

However, the present study had a number of limitations. First, although only medium- and high-quality studies were included, the 15 observational studies were of lower quality than randomized controlled trial which may have affected the objectivity of the major outcomes. Furthermore, delayed childhood growth in the included studies was defined using different guidelines, resulting in different ranges of percentiles or 1-3 standard deviations. These criteria may have overlapped; therefore, they were not distinguished in the subgroup analyses. In addition, the age, growth rate and hormone levels of each group of children may have been different in each study, which may have further impacted the results of the present study. As another possible limitation, environmental factors, inter-individual differences and iron deficiency anaemia may also lead to malnutrition in children; therefore, management 
Table V. Sensitivity analysis.

\begin{tabular}{llll}
\hline Author (year) & OR $(95 \%$ CI & Heterogeneity & Remainders' effect \\
\hline Raymond (1994) & $1.52(1.29-1.80)$ & $\mathrm{I}^{2}=1 \% ; \mathrm{P}=0.44$ & $\mathrm{Z}=4.89 ; \mathrm{P}<0.00001$ \\
Perri (1997) & $1.49(1.26-1.76)$ & $\mathrm{I}^{2}=0 \% ; \mathrm{P}=0.49$ & $\mathrm{Z}=4.69 ; \mathrm{P}<0.00001$ \\
Oderda (1998) & $1.50(1.27-1.78)$ & $\mathrm{I}^{2}=2 \% ; \mathrm{P}=0.43$ & $\mathrm{Z}=4.68 ; \mathrm{P}<0.00001$ \\
Cacciari (1999) & $1.50(1.27-1.77)$ & $\mathrm{I}^{2}=2 \% ; \mathrm{P}=0.43$ & $\mathrm{Z}=4.71 ; \mathrm{P}<0.00001$ \\
Choe (2000) & $1.50(1.27-1.78)$ & $\mathrm{I}^{2}=2 \% ; \mathrm{P}=0.42$ & $\mathrm{Z}=4.68 ; \mathrm{P}<0.00001$ \\
Buyukgebiz (2001) & $1.48(1.25-1.75)$ & $\mathrm{I}^{2}=0 \% ; \mathrm{P}=0.58$ & $\mathrm{Z}=4.62 ; \mathrm{P}<0.00001$ \\
Takahashi (2002) & $1.50(1.27-1.77)$ & $\mathrm{I}^{2}=0 \% ; \mathrm{P}=0.46$ & $\mathrm{Z}=4.78 ; \mathrm{P}<0.00001$ \\
Lin (2002) & $1.48(1.24-1.76)$ & $\mathrm{I}^{2}=0 \% ; \mathrm{P}=0.47$ & $\mathrm{Z}=4.44 ; \mathrm{P}<0.00001$ \\
Fialho (2007) & $1.47(1.23-1.75)$ & $\mathrm{I}^{2}=0 \% ; \mathrm{P}=0.47$ & $\mathrm{Z}=4.22 ; \mathrm{P}<0.0001$ \\
Cherian (2009) & $1.57(1.33-1.86)$ & $\mathrm{I}^{2}=0 \% ; \mathrm{P}=0.89$ & $\mathrm{Z}=5.28 ; \mathrm{P}<0.00001$ \\
Gulcan (2010) & $1.53(1.29-1.83)$ & $\mathrm{I}^{2}=0 \% ; \mathrm{P}=0.44$ & $\mathrm{Z}=4.75 ; \mathrm{P}<0.00001$ \\
Mendoza (2014) & $1.58(1.32-1.90)$ & $\mathrm{I}^{2}=0 \% ; \mathrm{P}=0.44$ & $\mathrm{Z}=4.89 ; \mathrm{P}<0.00001$ \\
Janjetic (2015) & $1.51(1.28-1.79)$ & $\mathrm{I}^{2}=2 \% ; \mathrm{P}=0.42$ & $\mathrm{Z}=4.85 ; \mathrm{P}<0.00001$ \\
Chiu (2017) & $1.51(1.28-1.79)$ & $\mathrm{I}^{2}=2 \% ; \mathrm{P}=0.42$ & $(34)$ \\
Benavides-Ward (2018) & $1.48(1.26-1.75)$ & $\mathrm{I}=0 \% ; \mathrm{P}=0.54$ & $(35)$ \\
\hline
\end{tabular}

OR, odds ratio.

A
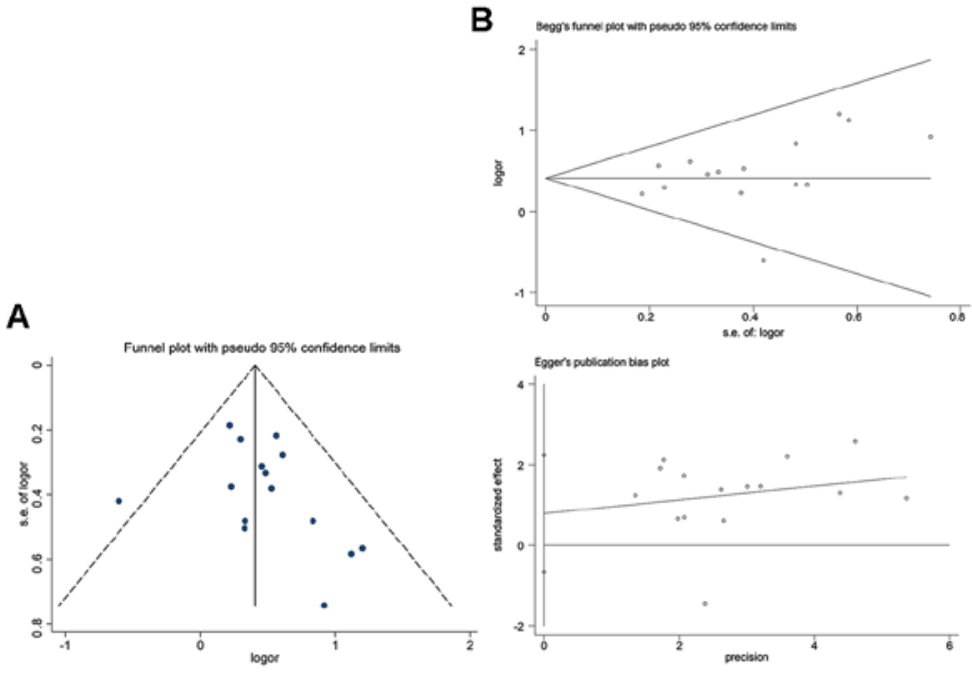

Bepo's Test

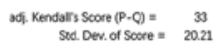

Nember of Sodies $=$ is

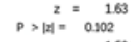

$Z=1.58$ (comonimily corrected

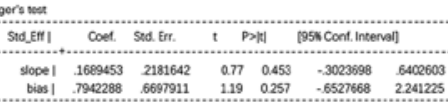

C

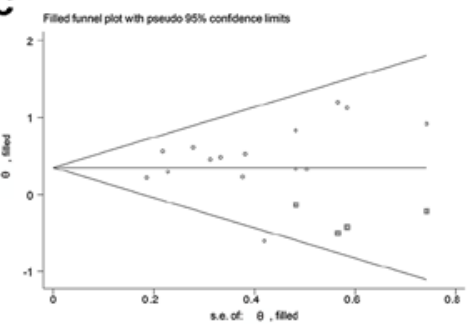

Metatrim logor selogor, funnel

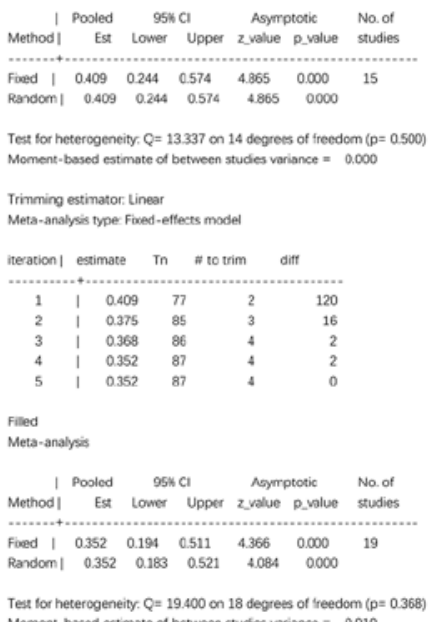

Test for heterogeneity $Q=19.400$ on 18 degrees of treedom $(\rho=0.560)$

Figure 10. Evaluation of publication bias. (A) Funnel plots. (B) No significant publication bias was detected by Begg's $(\mathrm{P}>\mathrm{z} \mathrm{z}=0.113)$ or Egger's $(\mathrm{P}>|\mathrm{t}|=0.257)$ linear regression analyses. (C) Adjusted funnel plot using the trim and fill method. The data-points in squares indicate supplementary studies. OR, odds ratio; Std.Dev., standard deviation; P>|t|, 2-tailed P-value; Std_Eff, standard efficiency; Coef, coefficient; Std.Err./s.e., standard error; Conf Interval, confidence interval; adj, adjusted.

of the growth and development of $H$. pylori-positive children should fully consider these comprehensive factors. Finally, omission of relevant published or unpublished studies may have influenced the conclusions made in the present study.

In conclusion, the present study suggested that $H$. pylori infection increased the likelihood of delayed childhood growth, particularly linear growth. The results suggested that children with delayed linear growth should be actively assessed and treated for H.pylori infection based on their antimicrobial susceptibility profile. Furthermore, it is necessary to establish a uniform standard definition for delayed childhood growth. Once diagnosed, the infection should be treated immediately to avoid further profound effects. Future extensive studies of vaccine strategies for the prevention of $H$. pylori infection 
in children are required. Furthermore, future high-quality and well-designed studies should be performed to further investigate the results obtained in the present study.

\section{Acknowledgements}

Not applicable.

\section{Funding}

The present study was supported by the National Natural Science Foundation of China (grant no. 81770561), the Jiangsu Medical Leading Talent and Innovation Team (grant no. CXTDA2017033) and the Jiangsu Province '333' Project (grant no. BRA2014332).

\section{Availability of data and materials}

The datasets used and/or analyzed during the present study are available from the corresponding author on reasonable request.

\section{Authors' contributions}

GZ and SW designed the study. SW and YD performed the literature search and extracted the data. LT, LP and XL analyzed the data. SW wrote the manuscript. All authors read and approved the final version of this manuscript.

\section{Ethical approval and consent to participate}

Not applicable.

\section{Patient consent for publication}

Not applicable.

\section{Competing interests}

The authors declare that they have no competing interests.

\section{References}

1. Khalifa MM, Sharaf RR and Aziz RK: Helicobacter pylori: A poor man's gut pathogen? Gut Pathog 2: 2, 2010.

2. Engstrand L and Lindberg M: Helicobacter pylori and the gastric microbiota. Best Pract Res Clin Gastroenterol 27: 39-45, 2013.

3. Plummer M, Franceschi S, Vignat J, Forman D and de Martel C: Global burden of gastric cancer attributable to Helicobacter pylori. Int J Cancer 136: 487-490, 2015.

4. Ford AC, Gurusamy KS, Delaney B, Forman D and Moayyedi P: Eradication therapy for peptic ulcer disease in Helicobacter pylori-positive people. Cochrane Database Syst Rev 4: CD003840, 2016.

5. Yamaoka Y: Mechanisms of disease: Helicobacter pylori virulence factors. Nat Rev Gastroenterol Hepatol 7: 629-641, 2010.

6. Hudak L, Jaraisy A, Haj S and Muhsen K: An updated systematic review and meta-analysis on the association between Helicobacter pylori infection and iron deficiency anemia. Helicobacter 22, 2017

7. Kalach N, Bontems P, Koletzko S, Mourad-Baars P, Shcherbakov P, Celinska-Cedro D, Iwanczak B, Gottrand F, Martinez-Gomez MJ, Pehlivanoglu E, et al: Frequency and risk factors of gastric and duodenal ulcers or erosions in children A prospective 1-month European multicenter study. Eur J Gastroenterol Hepatol 22: 1174-1181, 2010.
8. Bontems P, Kalach N, Vanderpas J, Iwanczak B, Casswall T, Koletzko S, Oderda G, Martinez-Gomez MJ, Urruzuno P, Kindermann A, et al: Helicobacter pylori infection in European children with gastro-duodenal ulcers and erosions. Pediatr Infect Dis J 32: 1324-1329, 2013.

9. McColl KE and el-Omar E: Helicobacter pylori and disturbance of gastric function associated with duodenal ulcer disease and gastric cancer. Scand J Gastroenterol Suppl 215: 32-37, 1996.

10. Dror G and Muhsen K: Helicobacter pylori infection and children's growth: An overview. J Pediatr Gastroenterol Nutr 62: e48-e59, 2016.

11. Yang YJ, Sheu BS, Yang HB, Lu CC and Chuang CC: Eradication of Helicobacter pylori increases childhood growth and serum acylated ghrelin levels. World J Gastroenterol 18: 2674-2681, 2012.

12. Jones NL, Koletzko S, Goodman K, Bontems P, Cadranel S, Casswall T, Czinn S, Gold BD, Guarner J, Elitsur Y, et al: Joint ESPGHAN/NASPGHAN guidelines for the management of Helicobacter pylori in children and adolescents (Update 2016). J Pediatr Gastroenterol Nutr 64: 991-1003, 2017.

13. Silva GM, Silva HM, Nascimento J, Goncalves JP, Pereira F and Lima R: Helicobacter pylori antimicrobial resistance in a pediatric population. Helicobacter 23: e12528, 2018.

14. Velin D, Straubinger K and Gerhard M: Inflammation, immunity, and vaccines for Helicobacter pylori infection. Helicobacter 21 (Suppl 1): S26-S29, 2016.

15. Okuda M, Nomura K, Kato M, Lin Y, Mabe K, Miyamoto R, Okumura A and Kikuchi S: Gastric cancer in children and adolescents in Japan. Pediatr Int 61: 80-86, 2019.

16. WHO Multicentre Growth Reference Study Group: WHO child growth standards based on length/height, weight and age. Acta Paediatr Suppl 450: 76-85, 2006.

17. de Onis M, Onyango AW, Borghi E, Siyam A, Nishida C and Siekmann J: Development of a WHO growth reference for school-aged children and adolescents. Bull World Health Organ 85: 660-667, 2007.

18. Benavides-Ward A, Vasquez-Achaya F, Silva-Caso W, Aguilar-Luis MA, Mazulis F, Urteaga N and Del Valle-Mendoza J: Helicobacter pylori and its relationship with variations of gut microbiota in asymptomatic children between 6 and 12 years. BMC Res Notes 11: 468, 2018.

19. Thomas JE, Dale A, Bunn JE, Harding M, Coward WA, Cole TJ and Weaver LT: Early Helicobacter pylori colonisation: The association with growth faltering in The Gambia. Arch Dis Child 89: 1149-1154, 2004.

20. Perri F, Pastore M, Leandro G, Clemente R, Ghoos Y, Peeters M, Annese V, Quitadamo M, Latiano A, Rutgeerts P and Andriulli A: Helicobacter pylori infection and growth delay in older children. Arch Dis Child 77: 46-49, 1997.

21. Fialho AM, Braga AB, Queiroz DM, Rodrigues MN, Herbster ID and Braga LL: The association between Helicobacter pylori infection and height in children from an urban community in north-east Brazil. Ann Trop Paediatr 27: 55-61, 2007.

22. Patel P, Mendall MA, Khulusi S, Northfield TC and Strachan DP: Helicobacter pylori infection in childhood: Risk factors and effect on growth. BMJ 309: 1119-1123, 1994.

23. Tasar A, Kibrisli E and Dallar Y: Seroprevalence of Helicobacter pylori in children with constitutional height retardation. Turk J Gastroenterol 17: 7-12, 2006.

24. Liu WZ, Xie Y, Lu H, Cheng H, Zeng ZR, Zhou LY, Chen Y, Wang JB, Du YQ, Lu NH, et al: Fifth Chinese national consensus report on the management of Helicobacter pylori infection. Helicobacter 23: e12475, 2018.

25. Bunn JE, Thomas JE, Harding M, Coward WA and Weaver LT: Placental acquisition of maternal specific IgG and Helicobacter pylori colonization in infancy. Helicobacter 8: 568-572, 2003.

26. Stroup DF, Berlin JA, Morton SC, Olkin I, Williamson GD, Rennie D, Moher D, Becker BJ, Sipe TA and Thacker SB: Meta-analysis of observational studies in epidemiology: A proposal for reporting. Meta-analysis of observational studies in epidemiology (MOOSE) group. JAMA 283: 2008-2012, 2000.

27. Moher D, Liberati A, Tetzlaff J and Altman DG; PRISMA Group: Preferred reporting items for systematic reviews and meta-analyses: The PRISMA statement. Int J Surg 8: 336-341, 2010.

28. Stang A: Critical evaluation of the Newcastle-Ottawa scale for the assessment of the quality of nonrandomized studies in meta-analyses. Eur J Epidemiol 25: 603-605, 2010. 
29. Hu J, Dong Y, Chen X, Liu Y, Ma D, Liu X, Zheng R, Mao X, Chen T and He W: Prevalence of suicide attempts among Chinese adolescents: A meta-analysis of cross-sectional studies. Compr Psychiatry 61: 78-89, 2015.

30. Higgins JP, Thompson SG, Deeks JJ and Altman DG: Measuring inconsistency in meta-analyses. BMJ 327: 557-560, 2003.

31. Belachew A and Tewabe T: Neonatal sepsis and its association with birth weight and gestational age among admitted neonates in Ethiopia: Systematic review and meta-analysis. BMC Pediatr 20: $55,2020$.

32. Raymond J, Bergeret M, Benhamou PH, Mensah $\mathrm{K}$ and Dupont C: A 2-year study of Helicobacter pylori in children. J Clin Microbiol 32: 461-463, 1994.

33. Choe YH, Kim SK and Hong YC: Helicobacter pylori infection with iron deficiency anaemia and subnormal growth at puberty. Arch Dis Child 82: 136-140, 2000.

34. Lin X: Study on risk factors of Helicobacter pylori infection and the effect of Helicobacter pylori infection on iron status and growth among preschool children (vol. Master). Fujian Med Univ, pp65, 2002.

35. Cherian S, Forbes D, Sanfilippo F, Cook A and Burgner D Helicobacter pylori, helminth infections and growth: A cross-sectional study in a high prevalence population. Acta Paediatr 98: 860-864, 2009.

36. Gulcan M, Ozen A, Karatepe HO, Gulcu D and Vitrinel A: Impact of $H$.pylori on growth: Is the infection or mucosal disease related to growth impairment? Dig Dis Sci 55: 2878-2886, 2010.

37. Mendoza E, Camorlinga-Ponce M, Perez-Perez G, Mera R, Vilchis J, Moran S, Rivera O, Coria R, Torres J, Correa P and Duque X: Present and past Helicobacter pylori infection in Mexican school children. Helicobacter 19: 55-64, 2014.

38. Janjetic MA, Mantero P, Cueto RE, Balcarce N, Zerbetto de Palma G, Catalano M, Zubillaga MB, Boccio JR and Goldman CG: Dietary and anthropometric indicators of nutritional status in relation to Helicobacter pylori infection in a paediatric population. Br J Nutr 113: 1113-1119, 2015.

39. Oderda G, Palli D, Saieva C, Chiorboli E and Bona G: Short stature and Helicobacter pylori infection in italian children: Prospective multicentre hospital based case-control study. The Italian study group on short stature and $H$. pylori. BMJ 317 : $514-515,1998$

40. Cacciari E, Menegatti M, Salardi S, Ali A, Stella FA, Figura N, Landi F, Holton J, Farinelli S, Cuccaro V, et al: Helicobacter pylori infection and cytotoxic antigen associated gene ' $\mathrm{A}$ ' status in short children. J Pediatr Endocrinol Metab 12: 197-201, 1999.

41. Büyükgebiz A, Dündar B, Böber E and Büyükgebiz B: Helicobacter pylori infection in children with constitutional delay of growth and puberty. J Pediatr Endocrinol Metab 14 549-551, 2001

42. Takahashi M, Kimura H and Watanabe K: Helicobacter pylori infection in patients with idiopathic short stature. Pediatr Int 44 277-280, 2002

43. Chiu NC, Lin CY, Chi H, Yeung CY, Ting WH, Chan WT, Jiang CB, Li ST, Lin CH and Lee HC: Helicobacter pylori infection is not associated with failure to thrive: A case control study. Ther Clin Risk Manag 13: 273-278, 2017.

44. Chilengi R, Asombang M, Kadota JL, Chilyabanyama ON, Mwila-Kazimbaya K, Ng'Ombe H,Simuyandi M and Bosomprah S: Early linear growth retardation: Results of a prospective study of Zambian infants. Bmc Public Health 19: 61, 2019.

45. Queiroz DM, Rocha AM and Crabtree JE: Unintended consequences of Helicobacter pylori infection in children in developing countries: Iron deficiency, diarrhea, and growth retardation. Gut Microbes 4: 494-504, 2013.

46. Ortiz-Princz D, Daoud G, Salgado-Sabel A and Cavazza ME: Helicobacter pylori infection in children: Should it be carefully assessed? Eur Rev Med Pharmacol Sci 20: 1798-1813, 2016.
47. Wroblewski LE and Peek RJ Jr: Helicobacter pylori in gastric carcinogenesis: Mechanisms. Gastroenterol Clin North Am 42: 285-298, 2013.

48. Serrano C, Wright SW, Bimczok D, Shaffer CL, Cover TL, Venegas A, Salazar MG, Smythies LE, Harris PR and Smith PD Downregulated Th17 responses are associated with reduced gastritis in Helicobacter pylori-infected children. Mucosal Immunol 6: 950-959, 2013.

49. Muhsen K, Ornoy A, Akawi A, Alpert G and Cohen D: An association between Helicobacter pylori infection and cognitive function in children at early school age: A community-based study. BMC Pediatr 11: 43, 2011.

50. Bazmamoun H, Rafeey M, Nikpouri M and Ghergherehchi R Helicobacter pylori infection in children with type 1 diabetes mellitus: A case-control study. J Res Health Sci 16: 68-71, 2016.

51. Xiong LJ and Mao M: Current views of the relationship between Helicobacter pylori and Henoch-Schonlein purpura in children. World J Clin Pediatr 5: 82-88, 2016.

52. Dehghani SM, Karamifar H, Raeesi $T$ and Haghighat $M$ : Growth parameters in children with dyspepsia symptoms and Helicobacter pylori infection. Indian Pediatr 50: 324-326, 2013.

53. Asgeirsdottir GA, Kjartansdottir I, Olafsdottir AS, Hreinsson JP, Hrafnkelsson H, Johannsson E and Bjornsson ES: Helicobacter pylori infection in Icelandic children. Scand J Gastroenterol 52: 686-690, 2017.

54. Nakayama Y, Lin Y, Hongo M, Hidaka H and Kikuchi S: Helicobacter pylori infection and its related factors in junior high school students in Nagano Prefecture, Japan. Helicobacter 22, 2017.

55. Shu X, Ping M, Yin G and Jiang M: Investigation of Helicobacter pylori infection among symptomatic children in Hangzhou from 2007 to 2014: A retrospective study with 12,796 cases. PeerJ 5: e2937, 2017

56. Awuku YA, Simpong DL, Alhassan IK, Tuoyire DA, Afaa T and Adu P: Prevalence of helicobacter pylori infection among children living in a rural setting in Sub-Saharan Africa. Bmc Public Health 17: 360, 2017.

57. Koletzko S, Jones NL, Goodman KJ, Gold B, Rowland M, Cadranel S, Chong S, Colletti RB, Casswall T, Elitsur Y, et al: Evidence-based guidelines from ESPGHAN and NASPGHAN for Helicobacter pylori infection in children. J Pediatr Gastroenterol Nutr 53: 230-243, 2011.

58. Ferwana M, Abdulmajeed I, Alhajiahmed A, Madani W, Firwana B, Hasan R, Altayar O, Limburg PJ, Murad MH and Knawy B: Accuracy of urea breath test in Helicobacter pylori infection: Meta-analysis. World J Gastroenterol 21: 1305-1314, 2015.

59. Leal YA, Flores LL, Fuentes-Pananá EM, Cedillo-Rivera R and Torres J: 13C-urea breath test for the diagnosis of Helicobacter pylori infection in children: A systematic review and meta-analysis. Helicobacter 16: 327-337, 2011.

60. Raj P, Thompson JF and Pan DH: Helicobacter pylori serology testing is a useful diagnostic screening tool for symptomatic inner city children. Acta Paediatr 106: 470-477, 2017.

61. Seo JH, Lim CW, Park JS, Yeom JS, Lim JY, Jun JS, Woo HO, Youn HS, Baik SC, Lee WK, et al: Correlations between the CagA antigen and serum levels of anti-Helicobacter pylori $\mathrm{IgG}$ and IgA in children. J Korean Med Sci 31: 417-422, 2016.

62. Romano C, Valenti S, Cardile S and Benninga MA: Functional dyspepsia: An enigma in a conundrum. J Pediatr Gastroenterol Nutr 63: 579-584, 2016

This work is licensed under a Creative Commons Attribution-NonCommercial-NoDerivatives 4.0 International (CC BY-NC-ND 4.0) License. 